\title{
Neurodevelopmental profile in Angelman syndrome: more than low intelligence quotient
}

\author{
S. Micheletti ${ }^{1,2,4^{*}}$, F. Palestra ${ }^{1,3}$, P. Martelli ${ }^{4}$, P. Accorsi ${ }^{4}$, J. Galli ${ }^{1,3,4}$, L. Giordano ${ }^{4}$, V. Trebeschi ${ }^{4}$ and E. Fazzi ${ }^{3,4}$
}

\begin{abstract}
Background: Angelman Syndrome (AS) is a rare neurodevelopment disorder resulting from deficient expression or function of the maternally inherited allele of UBE3A gene. The aim of the study is to attempt at providing a detailed definition of neurodevelopmental profile in AS, with particular regard to motor, cognitive, communicative, behavioural and neurovisual, features by using standardized instruments.

Method: A total of ten subjects aged from 5 to 11 years ( 4 males and 6 females) with molecular confirmed diagnosis of AS (7 15q11.2-q13 deletion and 3 UBE3A mutation) were enrolled in our study. All of them underwent an assessment protocol including neurological and neurovisual examination and the evaluation of motor (Gross Motor Function Measure Scale), cognitive (Griffiths Mental Development Scale and Uzgiris-Hunt Scale); adaptive (Vineland Adaptive Behavioural Scale); communication (MacArthur-Bates Communicative Development Inventory and video-recordings children's verbal expression), behavioural aspects (IPDDAG Scale) and neurovisual aspects.

Results: All children presented motor function involvement. A severe cognitive impairment was detected with different profiles according to the test applied. In all cases, communicative disability (phonemic inventory, word/ gesture comprehension and production) and symptoms of inattention disorder were revealed. Neurovisual impairment was characterized by refractive errors, fundus oculi anomalies, strabismus and/or oculomotor dysfunction.

Conclusion: AS presents a complex neurodevelopmental profile in which several aspects play a negative role in global development leading to a severe functional impairment. Intellectual disability is not the only component because neurovisual functions and behavioural disorders may worsen the global function and are needed of specific rehabilitation programs.
\end{abstract}

Keywords: Angelman syndrome, Motor impairment, Neurovisual disorder, Intellectual disability, Communicative disorders

\section{Background}

Angelman syndrome (AS) is a rare neurodevelopment disorder with resulting from deficient expression or function of the maternally inherited allele of UBE3A gene on chromosome 15, which plays an important role in the cellular ubiquitin-proteasome pathway and synaptic development [1].

Four genotypic mechanisms that confer the AS phenotype are currently known, i.e., deletion or mutation of

\footnotetext{
* Correspondence: serena.micheletti01@universitadipavia.it

${ }^{1}$ Unit of Child Neuropsychiatry and Early Neurorehabilitation, ASST Spedali Civili, Piazzale Spedali, Civili 1, 25123 Brescia, Italy

${ }^{2}$ Cognition Psychology Neuroscience Lab, University of Pavia, Pavia, Italy

Full list of author information is available at the end of the article
}

the maternal UBE3A gene, paternal uniparental disomy, or an imprinting defect [2].

Even if research into genotype-phenotype correlations reveals a more severe impairment among children with deletion forms rather than those with other genetic mechanisms [3, 4], all genetic expressions lead to a similar clinical phenotype [5] characterized by developmental delay, movement or balance disorder, specific behavioural characteristics and speech impairment [6].

The behavioural characteristics of AS are present in all patients irrespective of the type of genetic abnormality and often prompt clinicians to consider the diagnosis [7]. Apparent happiness is the hallmark of the syndrome, 
associated with profuse smiling, poorly specific laughing and general exuberance, with hyperactivity, stereotypes, and proactive social contact [8].

Cognitive delay is usually evident within the first year of life [9] and in the few studies that applied psychometric assessments most patients reach plateau at a developmental level of 24-30 months [10-12]. 80-90\% of AS patients are reported to have epilepsy [13]. In particular atypical absence, myoclonic, generalized tonic-clonic, and atonic seizures [14].

Truncal hypotonia and distal extremity hypertonia/ hyperreflexia characterize the neurological examination of children with AS [15]. Movement disturbances such as jerkiness, ataxic gait and tremors are specific; abnormalities of tone and impaired balance contribute to the delayed acquisition of motor skills (sitting after 12 months, walking between 2 and 6 years) [9].

Communication difficulties are prominent features in AS. Most patients do not acquire expressive speech or have a vocabulary of few words [12]; some can communicate using sign language and others can use gesture or augmentative communication devices [7, 9]. Common language assessment tools are difficult to apply and receptive-expressive skills have been mostly analysed by parents' reports $[12,16]$.

As regards daily living skills only few studies have applied standardized instruments to explore adaptive behaviour profiles in AS $[4,11,17]$. Peters and colleagues [11] proposed to parents the Vineland Adaptive Behaviour Scales (VABS) and found a relative strength in socialisation and a weakness in motor skills in a group of 20 patients aged 5 months- 10 years. Brun Gasca and colleagues [18] proposed the Inventory for Client Agency in a group of 25 children with AS aged 117 years and found highest scores in personal living skills and lowest for social and communication skills.

Poor data are also reported on visual problems in AS population. Ocular problems in AS include refractive errors (usually hypermetropia and astigmatism), iris and choroidal hypopigmentation, and esotropia or exotropia $[19,20]$. They are more common in those with deletion. Nystagmus is reported but is not common.

Despite many descriptive data documenting the cognitive, linguistic and behavioural profiles of AS, no studies, to our knowledge, provide a comprehensive description of the clinical profile of AS collecting and relating different developmental areas such as motor, neurovisual, linguistic, cognitive, adaptive and behavioural features.

The aim of the study was to analyse these neurodevelopmental areas that concur in the development of AS patients, and to describe a specific neurodevelopmental clinical profile which can be the basis to promote tailored early intervention programs.

\section{Methods}

\section{Participants}

All the children at scholar age (5 to 11 years) with a molecular confirmed diagnosis of AS, referred to our Department between 2013 and 2015, have been enrolled. Exclusion criteria were the presence of epilepsy not controlled by antiepileptic drugs and the presence of intercurrent diseases. Ten subjects were recruited: 4 males and 6 females, age ranging from 5 years and 2 months to 11 years (mean age 7 years and 1 month; SD 1 year and 7 months).

Demographic, genetic and clinical characteristics are reported in Table 1.

In 7 children UBE3A deletion (DEL) was detected and in 3 patients a UBE3A mutation (MUT) was present. The age at the diagnosis varied according to the type of genotypic mechanism: patients with DEL were diagnosed between 9 and 36 months (mean 17.4 months SD 9.7), those with MUT were diagnosed later (mean 30.6, SD 6.7). Birth weight (mean 2931 gr, SD 428 gr) and head circumference (mean $33.5 \mathrm{~cm}$; SD $1.15 \mathrm{~cm}$ ) at birth were

Table 1 Clinical characteristics of the sample

\begin{tabular}{|c|c|c|c|c|c|c|c|}
\hline Genetic anomaly & Patient & Age & Sex & Age at diagnosis & Pregnancy & GA & Perinatality \\
\hline \multirow[t]{3}{*}{ UBE3A mut } & Pat.1 & 8 yr $11 \mathrm{mo}$ & M & $34 \mathrm{mo}$ & Normal & Term & Normal \\
\hline & Pat. 2 & $5 \mathrm{yr} 2 \mathrm{mo}$ & $\mathrm{F}$ & $35 \mathrm{mo}$ & Normal & Term & Normal \\
\hline & Pat. 3 & $8 \mathrm{yr} 1 \mathrm{mo}$ & $\mathrm{F}$ & $23 \mathrm{mo}$ & Normal & Term & Normal \\
\hline \multirow[t]{7}{*}{ Deletion } & Pat. 4 & $5 \mathrm{yr} 3 \mathrm{mo}$ & M & $11 \mathrm{mo}$ & Normal & Term & Normal \\
\hline & Pat. 5 & 6 yr 5 mo & M & $9 \mathrm{mo}$ & Gestosis & Preterm & C section \\
\hline & Pat. 6 & $10 \mathrm{yr}$ & M & $13 \mathrm{mo}$ & Normal & Term & Normal \\
\hline & Pat. 7 & $6 \mathrm{yr} 7 \mathrm{mo}$ & $\mathrm{F}$ & $10 \mathrm{mo}$ & Normal & Term & Normal \\
\hline & Pat. 8 & 8 yr 2 mo & $\mathrm{F}$ & $22 \mathrm{mo}$ & Normal & Term & Normal \\
\hline & Pat.9 & $6 \mathrm{yr} 4 \mathrm{mo}$ & $\mathrm{F}$ & $36 \mathrm{mo}$ & Normal & Term & Normal \\
\hline & Pat. 10 & 3 yr $11 \mathrm{mo}$ & $\mathrm{F}$ & $21 \mathrm{mo}$ & IUGR & Term & Normal \\
\hline
\end{tabular}


within normal range in 9 patients. On the contrary, 5 patients presented a head circumference below third centiles and 4 subjects had weight and height below normal range at the moment of protocol submission.

All children except two had epilepsy and needed antiepileptic drugs (valproic acid in 2 patients, associated with etosuccimide, levetiracetam or clobazam in 5 patients, clonazepam in 1 patient). 7 patients have started antiepileptic therapy since they were younger than 2 years old. One patient started therapy when she was 3 years old. All patients were seizure-free.

Neuro-imaging was normal in 3 subjects, in 5 subjects mild periventricular anomalies were detected. Two children did not undergo neuroimaging exams because of parents' refusal.

\section{Procedure}

An evaluation protocol including motor abilities, cognitive and adaptive functions, language and communication skills, behavioural aspects and neurovisual functions was proposed to all families. Evaluation was composed both by clinical assessments and by parents' questionnaires. Ethical Committee of ASST Spedali Civili in Brescia, Italy, approved the study and informed consent was obtained from parents.

Motor function was evaluated by the collection of anamnestic data especially about motor milestones, Gross Motor Function Measure Scale (GMFMS) [21] and neurological examination.

Because of the difficulties to propose intelligence scales according to chronological ages (massive presence of floor effects on intelligence tests such as Leiter-r scale) [22], all the children were assessed by using Griffiths Mental Developmental Scales (GMDS) [23] and Uzgiris Hunt Scale
(UHS) [24], based on Piaget's theory of intelligence development [25]. VABS [26] were proposed to the parents to evaluate adaptive functions.

Because of the subjects' reduced compliance on standardized language tests, communication and receptive/ expressive language abilities were analysed by the Italian version of the MacArthur-Bates Communicative Development Inventory (PVB) [27], and the video-recordings children's verbal expression during a structured child playing observation. PVB was proposed to compare action/gesture production, word comprehension/production and the relationship between these three domains. An investigation into phonemic inventory was obtained by recording and analysing child speech production during semi-structured playing observation.

The Italian questionnaire IPDDAG [28] was proposed, according to patient's mental age (MA) to investigate behavioural aspects, particularly those referred to Attention Deficit and Hyperactive Disorder (ADHD) symptoms.

All participants underwent a clinical and neurovisual assessment [29] that includes the evaluation of ophthalmological aspects (refraction under cycloplegia, anterior segment and fundus oculi), oculomotor components (visual axis alignment to detect strabismus, extrinsic ocular motility, fixation, smooth pursuit, saccades, abnormal ocular movements), perceptual visual elements (visual acuity, contrast sensibility, optokinetic nystagmus and visual field) and visual attention.

\section{Results}

\section{Motor and physical evaluation}

Table 2 details motor abilities in the sample.

Anamnestic data revealed that all the subjects presented delay in motor milestones (mean age head

Table 2 Motor development and GMFMS evaluation results

\begin{tabular}{|c|c|c|c|c|c|c|c|c|c|c|}
\hline & & \multirow[t]{2}{*}{ Head control } & \multirow[t]{2}{*}{ Sitting } & \multirow[t]{2}{*}{ Walking } & \multicolumn{6}{|c|}{ GMFMS } \\
\hline & & & & & $L R$ & $\mathrm{Si}$ & CK & St & WRJ & TS \\
\hline \multirow[t]{4}{*}{ UBE3A mut } & Pt 1 & $7 \mathrm{mo}$ & $9 \mathrm{mo}$ & $30 \mathrm{mo}$ & 100 & 100 & 88 & 82 & 65 & 87 \\
\hline & Pt 2 & $5 \mathrm{mo}$ & $10 \mathrm{mo}$ & $24 \mathrm{mo}$ & 100 & 98 & 88 & 77 & 36 & 80 \\
\hline & Pt 3 & $4 \mathrm{mo}$ & $16 \mathrm{mo}$ & $23 \mathrm{mo}$ & 100 & 100 & 95 & 82 & 49 & 85 \\
\hline & Mean & $5 \mathrm{mo}$ & $12 \mathrm{mo}$ & $26 \mathrm{mo}$ & 100 & 99 & 91 & 81 & 50 & 84 \\
\hline \multirow[t]{8}{*}{ Deletion } & Pt 4 & $4 \mathrm{mo}$ & $15 \mathrm{mo}$ & $36 \mathrm{mo}$ & 100 & 100 & 85 & 82 & 43 & 82 \\
\hline & Pt 5 & $4 \mathrm{mo}$ & $10 \mathrm{mo}$ & $48 \mathrm{mo}$ & 100 & 100 & 83 & 80 & 40 & 80 \\
\hline & Pt 6 & $5 \mathrm{mo}$ & $13 \mathrm{mo}$ & $24 \mathrm{mo}$ & 100 & 100 & 100 & 77 & 43 & 84 \\
\hline & Pt 7 & $9 \mathrm{mo}$ & $24 \mathrm{mo}$ & $48 \mathrm{mo}$ & 100 & 100 & 88 & 33 & 17 & 68 \\
\hline & Pt 8 & $8 \mathrm{mo}$ & $19 \mathrm{mo}$ & $72 \mathrm{mo}$ & 100 & 97 & 31 & 46 & 25 & 60 \\
\hline & Pt 9 & $10 \mathrm{mo}$ & $24 \mathrm{mo}$ & $48 \mathrm{mo}$ & 100 & 100 & 90 & 46 & 28 & 73 \\
\hline & Pt 10 & $5 \mathrm{mo}$ & $8 \mathrm{mo}$ & $30 \mathrm{mo}$ & 100 & 100 & 87 & 40 & 85 & 19 \\
\hline & Mean & $6 \mathrm{mo}$ & $16 \mathrm{mo}$ & $43 \mathrm{mo}$ & 100 & 99 & 80 & 57 & 34 & 66 \\
\hline Total & Mean & $6 \mathrm{mo}$ & $14 \mathrm{mo}$ & $38 \mathrm{mo}$ & 100 & 99 & 83,5 & 64,5 & 43 & 72 \\
\hline
\end{tabular}

mo months, $L R$ Lying and Rolling, Si sitting, CK crawling and kneeling, St standing, WRJ walking, running and jumping, TS total score 
control 6.9 months, SD 2.8; sitting 16.2 months, SD 6.3; walking 38.3 months, SD 15.6), also confirmed by GMFMS, which showed a homogeneous profile among the patients with a mild motor impairment in standing ability and a more severe impairment in walking tasks. Children with DEL reached motor milestones later (mean age head control 7.4 months, SD 2.9; sitting 18.1 months, SD 6.4; walking 43.4 months, SD 15, 8) than those with MUT (mean age head control months, sitting 11, 7 months, walking 25, 7 months).

In all the subjects, neurological examination detected ataxia and motor stereotypes, which were associated with tremor/jerky movements in 2 patients, distal hypertonia at lower limbs in 5 patients, hypotonia in 2, scoliosis in 1 .

\section{Cognitive evaluation}

Cognitive evaluation with GMDS showed the presence of severe intellectual disability in the whole sample. The definition of mental age (MA) was preferred instead of the measurement of Developmental Quotient. Most of the patients presented in fact severe difficulties which are not effectively described by centiles (all the patients were below the first centile in all the subscales). The mean MA of the total score was 14.1 months (SD 4.7; range 9.3-23). None of the patients reached a MA higher than 24 months. The profile in each subscale was substantially homogeneous. Higher scores were obtained in Locomotor (mean MA 17.3 months; SD 5.6; range 11-27) and Personal and Social subscales (mean MA 15.8 months; SD 6.5; range 8-24.6). Lowest scores characterized Language (mean MA 11.4 months; SD 3.2; range 7.5-15.6) and Performance Scales (mean MA 12.5 months; SD 3.2; range 6.5-21).

Cognitive impairment was more severe in DEL group (mean MA 11.7 months; SD 1.7; range 9.3-17) than in MUT group (mean MA 19.7 months; SD 3; range 17-23).
In order to obtain a qualitative perspective, the sample underwent an evaluation with UHS, which confirmed the presence of a severe intellectual disability. Because of the ceiling effect two patients reached the highest values in the majority of the subscales (see Table 3), showing thus a MA greater than 24 months. Four children mastered cognitive precursors of language, since they reached at least the fifth stadium at the Object Permanence, Means ends and Operational Causality subscales. These were the only children who performed deictic gesture and showed the highest level of word expression.

\section{Adaptive functions}

VABS showed a severe impairment in all the investigated domains. In some scales the majority of the patients showed a floor effect on those scales which imply a level of competences usually reached over 24 months (written, domestic, coping skills, interpersonal relationships subdomains). Thus these scales did not provide reliable information about the real skills of the subjects. The area of Communication skills (receptive, expressive, and written communication skills) was the most affected: 8 patients showed a floor effect (MA $<18$ months). Daily living domain was also severely affected: 5 patients showed a MA lower than 18 months. A MA of 37 months was reached by a MUT patient who also showed the best scores at cognitive evaluation. In Socialization domain (Interpersonal Relationships, Play and Leisure Time, Coping skills) 3 patients showed the lowest scores (floor effect), the other patients showed competences between 18 and 26 months (mean 21 months; SD 2, 8).

Scores at Motor skills domain were heterogeneous: 4 patients scored lower than 18 months, two children reached a score higher than 24 months. Children with MUT showed better competences in all the adaptive

Table 3 GMDS evaluation and communicative and linguistic findings at PVB

\begin{tabular}{|c|c|c|c|c|c|c|c|c|c|c|c|c|}
\hline & & \multicolumn{4}{|c|}{ GMDS (MA in months) } & \multirow[b]{2}{*}{$P$} & \multirow[b]{2}{*}{$\mathrm{T}$} & \multicolumn{3}{|c|}{ PVB (MA in months) } & \multirow[b]{2}{*}{ PP } & \multirow[b]{2}{*}{ DG } \\
\hline & & $\bar{M}$ & PS & L & $\mathrm{EHC}$ & & & WC & WP & AGP & & \\
\hline \multirow[t]{3}{*}{ UBE3A mut } & Pt 1 & 20 & 22 & 14 & 22 & 21 & 19 & $>17$ & $<8$ & 17 & No & Yes \\
\hline & Pt 2 & 27 & 25 & 16 & 24 & 20 & 23 & $>17$ & 14 & $>17$ & No & Yes \\
\hline & Pt 3 & 25 & 23 & 13 & 17 & 14 & 17 & 17 & $<8$ & 14 & No & Yes \\
\hline \multirow[t]{7}{*}{ Deletion } & Pt 4 & 19 & 15 & 13 & 13 & 10 & 14 & 11 & $<8$ & 10 & No & No \\
\hline & Pt 5 & 8 & 7 & 9 & 8 & 9 & 13 & 12 & $<8$ & 12 & No & No \\
\hline & P 6 & 19 & 11 & 8 & 10 & 6 & 11 & 13 & $<8$ & 10 & No & No \\
\hline & Pt 7 & 9 & 8 & 9 & 9 & 9 & 13 & 8 & $<8$ & 9 & No & No \\
\hline & Pt 8 & 12 & 10 & 10 & 8 & 9 & 10 & 11 & $<8$ & 11 & No & No \\
\hline & Pt 9 & 13 & 12 & 9 & 11 & 9 & 12 & 15 & $<8$ & 21 & No & Yes \\
\hline & Pt 10 & 16 & 22 & 15 & 19 & 17 & 17 & 13 & $<8$ & 15 & No & Yes \\
\hline
\end{tabular}

GMDS-R Scales: $M$ Motor, $P S$ personal social, $L$ language, $E H C$ eye hand coordination, $P$ performance, $T$ total

PVB: WC word comprehension, WP word production AGP action/gesture production, PP pretend play, DG deictic gestures 
domains. In particular, they presented better performance in personal and gross motor skills.

\section{Language and communication}

The evaluation of word comprehension/production and action/gesture production (routines gestures, actions with objects, pretending play and imitation gestures) revealed a severe impairment of early communication skills. The mean word comprehension MA was 14.1 months (DS 3.7; range 8-18). Word production MA was not evaluated because of the presence of floor effect in the entire sample. Three children could speak up to 5 words.

In most of the cases the difference between the understood and spoken words was extremely high.

The mean action/gesture production MA was 12.5 months (DS 12.5; range 10-17) and the best represented actions/ gestures concerned playing/routines activities (mean percentage gesture comprehension: $48 \%$ ). None of the patients were able to access to pretending play skills. Four children had deictic gestures and 6 had other referential gestures. As regards phoneme inventory, all patients were able to pronounce the " $\boldsymbol{a}$ " vowel. Consonants were present only in four patients, who could pronounce nasal and stop consonants (see Table 4).

\section{Behavioural profile}

All patients except one scored above the $95^{\text {th }}$ centile in the attention deficit scale. Seven subjects had scores higher than $95^{\text {th }}$ centile in hyperactive disorder scale, the other patients had scores between $50^{\text {th }}-75^{\text {th }}$ and $90^{\text {th }}$ $95^{\text {th }}$ centile. All except one had scores higher than $95^{\text {th }}$ centile in the total scale.

\section{Neurovisual evaluation}

Table 5 summarizes neurovisual evaluation results. All the children presented refractive errors (most of them had

Table 4 Phoneme inventory (number of patients who can pronounce consonants/vowels)

\begin{tabular}{|c|c|c|c|c|c|c|c|c|}
\hline \multicolumn{9}{|c|}{ Phoneme inventory } \\
\hline \multicolumn{9}{|c|}{ Consonantic inventory } \\
\hline & & & $\mathrm{m}$ & $n$ & $\eta$ & $\mathrm{p}$ & $\mathrm{t}$ & \\
\hline \multirow[t]{4}{*}{ Position } & Initial & Deletion & 1 & / & / & 1 & 0 & 1 \\
\hline & & UBE3A mut & 1 & 1 & / & 1 & 1 & 1 \\
\hline & Median & Deletion & 1 & & / & 1 & 1 & 1 \\
\hline & & UBE3A mut & 1 & 1 & / & 0 & 1 & 0 \\
\hline \multicolumn{9}{|c|}{ Vocalic inventory } \\
\hline & & & i & e & $\varepsilon$ & a & 4 & o \\
\hline & Tonic & Deletion & / & / & 1 & 7 & / & / \\
\hline & & UBE3A mut & 1 & 1 & 1 & 3 & 1 & / \\
\hline & Atonic & Deletion & / & / & / & 2 & / & / \\
\hline & & UBE3A mut & 1 & 1 & / & 2 & l & / \\
\hline
\end{tabular}

hypermetropic astigmatism) and 5 had a hypopigmentation of fundus oculi. Strabismus (especially exotropia) was documented in six subjects, unstable visual fixation in three, discontinuous smooth pursuit in six and mild difficulties to perform voluntary saccades were observed in four children. None of the subjects presented visual perceptual deficit (visual acuity was near normal and all the subjects were able to locate targets presented in different areas of the visual field). Screening of visuocognitive abilities was not possible because of the severe intellectual delay of the whole sample, which also showed a moderate to severe visual attention impairment.

\section{Discussion}

This study has permitted to evaluate the neurodevelopmental aspects of a group of subjects with AS. Despite the small number of subjects, a high homogeneity of the results has been found among those evaluated, as literature data shows [4].

With reference to motor skills, a delay in acquiring motor milestones (head control, sitting and walking) has been documented. In particular, the acquisition of walking skills seems to be the most difficult milestone to reach, with significant differences between DEL and MUT groups. Ataxia has seemed to threaten the access to more complex GMFMS tasks, such as Standing and Walking ones. To our knowledge, no previous studies with GMFMS in AS children are reported in literature even if it could be considered an interesting standardized instrument to describe the motor functional disability in AS population. Clinicians should consider the opportunity to evaluate neuromotor abilities early, in order to promote at first, the achievement of motor milestones.

Cognitive assessment, proposed throughout psychometric tests and instruments which give a qualitative evaluation of cognitive competences, confirmed the severe intellectual disability as reported in literature $[11,12]$. The psychometric evaluation by GMDS showed that none of sample reached 24 months of MA with a mean MA of 14.1 months, while the qualitative evaluation by UHS showed the achievement of ceiling effects in most of UHS subscales in 2 children out of 10 . The presence of better performances in UHS scales than in GMDS can probably be explained by the different approaches to cognitive evaluation: most of the tasks included in psychometric instruments, as GMDS, are based on precise instructions that directly indicate what is expected. Responses typically have a verbal component, which is another factor that affects AS patients who cannot speak more than few words. In UHS scales, no direct indications are provided, but only the elicitation of behaviours as a consequence of the presentation of a stimulus.

As regards adaptive functions evaluated by VABS, communication and daily living skills were the most 
Table 5 Neurovisual features

\begin{tabular}{|c|c|c|c|c|c|c|c|c|c|c|c|}
\hline Sbj & $\begin{array}{l}\text { Refr. } \\
\text { errors }\end{array}$ & $\begin{array}{l}\text { Fundus } \\
\text { oculi }\end{array}$ & $\begin{array}{l}\text { Visual } \\
\text { fixation }\end{array}$ & $\begin{array}{l}\text { Smooth } \\
\text { pursuit }\end{array}$ & Saccades & Strabismus & $\begin{array}{l}\text { Abnormal ocular } \\
\text { movement }\end{array}$ & $\begin{array}{l}\text { Visual } \\
\text { acuity }\end{array}$ & $\begin{array}{l}\text { Contrast } \\
\text { sensitivity (\%) }\end{array}$ & $\begin{array}{l}\text { Visual } \\
\text { field }\end{array}$ & $\begin{array}{l}\text { Visual } \\
\text { attention }\end{array}$ \\
\hline Pat. 1 & $A, I$ & Normal & Altered & Altered & Normal & Exotropia & No & $6.3 / 10$ & 1.25 & Normal & Altered \\
\hline Pat. 2 & $A, I$ & Normal & Normal & Normal & Normal & No & No & $6.3 / 10$ & 1.25 & Normal & Altered \\
\hline Pat. 3 & $A, I$ & Normal & Normal & Altered & Altered & Exo-hypotropia & No & 13 cy/deg & 1.25 & Normal & Altered \\
\hline Pat. 4 & $A, I$ & Normal & Normal & Altered & Altered & Esotropia & No & 9.6 cy/deg & 5 & Normal & Altered \\
\hline Pat. 5 & $A, I$ & Hypop. & Altered & Altered & Normal & No & No & 9.6 cy/deg & 1.25 & Normal & Altered \\
\hline Pat. 6 & $A, I$ & Hypop. & Normal & Altered & Normal & Exotropia & No & 9.6 cy/deg & 1.25 & Normal & Altered \\
\hline Pat. 7 & $A, I$ & Hypop & Altered & Altered & Altered & Exotropia & No & 9.6 cy/deg & 1.25 & Normal & Altered \\
\hline Pat. 8 & $A, M$ & Hypop. & Normal & Normal & Normal & Exotropia & No & 9.6 cy/deg & 1.25 & Normal & Altered \\
\hline Pat. 9 & $A, I$ & Normal & Normal & Normal & Altered & No & No & 14 cy/deg & 5 & Normal & Altered \\
\hline Pat. 10 & A & Hypop. & Normal & Normal & Normal & No & No & 14 cy/deg & 1.25 & Normal & Altered \\
\hline
\end{tabular}

$A$ astigmatism, I hypermetropia, M myopia, Hypop hypopigmentation, OD optic disc, Ny latent nystagmus with horizontal jerky

affected scales, as most of the subjects' performance showed floor effect. MUT subjects showed better abilities especially in personal and gross motor skills.

With reference to language abilities, a severe impairment of receptive and expressive skills has been found at all ages. To our knowledge this is the first study that has identified the peculiar repertoire of word comprehension, phonemic inventory and referential gestures in AS.

Receptive competences could reach the second year of MA and were characterized in the entire sample, irrespective of the age, by a major comprehension level of those words that are typically understood even during the first stages by the Italian infant population [30].

The same trend has been identified in phoneme processing development: the entire sample can only acquire some nasal and occlusive phonemes, as it normally happens in the first steps of Italian phoneme acquisition [31].

Only some children with AS showed gesture competences such as referential and deictic gestures and none of them presented pretending play skills, which involves language use and takes place in social contexts. Expressive language speech wasn't present, despite the presence of cognitive precursors of language in 4 children and the presence of deictic gesture in 4 .

These findings suggest the role of other factors which could be related to language development in AS. Penner and colleagues [32] refer respectively to stage 5 and 6 as a prerequisite for language and speech development. Even considering only the subjects who reached the sixth stage, none of them was able to speak more than five words. These results let us hypothesize that the lack of expressive language is not simply justified by the severe intellectual disability in AS population. Neither difficulties in interpersonal relationships seem to be the cause of expressive disorders since communicative inputs emerged from VABS, UHS and PVB. We could not administer ADOS scales because of the presence of MA lower than 12 months in 5 children.

Oller and colleagues [33] analyzed the importance of babbling as one of the prerequisites for later speech development. None of the subjects had normal babbling patterns, suggesting a massive impairment of the phonoarticulation networks as a determinant cause of the lack of language production. Moreover, recent DTI Magnetic Resonances in AS have shown alterations in associated tracts and in particular in left arcuate fasciculus which reveals severe morphological changes, leading to hypothesize a generalized white matter alteration [34]. More studies are needed to better understand the mechanisms, which underline AS language competences impairment.

Our study demonstrates the importance of evaluating visual function in AS. The reduced pigmentation of fundus oculi can be explained by the haplo-insufficiency of OCA2 gene, which is involved in the development of pigment in the skin, hair, and eyes and located close to UBE3A gene [35].

Refractive errors (especially characterized by astigmatism associated with hypermetropia) were detected in all the subjects, esotropia was documented in one patient, exotropia in four and exo-hypotropia in one. To our knowledge, only one study reported the same results [20]. The presence of refractive errors in all the AS sample underlines the importance of an early neurovisual evaluation to detect the type of refractive errors and to prescribe optical devices. An early correction of refractive errors can ameliorate visual acuity for activities of daily living and finally can promote the development of cognitive functions, as has been documented in patients with other genetic syndromes [36]. The oculomotor abilities, evaluated from a qualitative point of view, were impaired in AS: fixation was unstable, smooth 
pursuit discontinuous and saccades mild impaired. The role of the oculomotor disorders is not clear but our previous experiences in other neurological pathologies documented a relation between oculomotor impairment and attention deficit [37]. Even if this relation is not clear and further studies on larger samples are necessary, an early identification of oculomotor disorders and early promotion of oculomotor functions may have a positive effect on attention deficit.

Visual perceptual abilities were difficult to evaluate because of children poor compliance. We can however infer, throughout the normal contrast sensitivity and the ability to locate targets presented in different areas of the visual field, that there were not any major visual perceptual problems. Moreover, using preferential looking procedure we observed a mild reduction in visual acuity that could be an expression of uncorrected refractive errors.

\section{Conclusions}

This study represents one of the first attempts to analyze and integrate clinical aspects typical of AS, throughout the usage of qualitative and psychometric assessment tools.

The results demonstrate that AS clinical profile could be considered as a consequence of several aspects that interact each other and play a negative role on global development. Neurovisual problems, with particular regard to refractive errors and to oculomotor impairment should be taken into account at early stages of development because they could be related to and can later influence cognitive and attentional functions. Origin of the peculiar language disorders is not still clear and cannot be simply justified by the lack of cognitive prerequisites.

These data suggest that an early and careful assessment of motor, neurovisual, cognitive, linguistic and attention abilities should be essential for a correct identification of strengths and weaknesses of this clinical population so as to plan tailored rehabilitation programs, based on the promotion of motor milestones, neurovisual function and communication abilities during the first stages of life.

\section{Abbreviations \\ ADHD: Attention Deficit and Hyperactive Disorder; AS: Angelman syndrome; DEL: UBE3A deletion; GMDS: Griffiths Mental Developmental Scales; GMFMS: Gross Motor Function Measure Scale; MA: Mental age; MUT: UBE3A mutation; PVB: MacArthur-Bates Communicative Development Inventory; UHS: Uzgiris Hunt Scale; VABS: Vineland Adaptive Behaviour Scales}

\section{Acknowledgements}

The authors thank Micaela De Simone (neuropsychiatrist), Anna Alessandrini, Nicole D'Adda and Maria Fezzardi (occupational therapists), Nadia Pasini and Alessandra Franzoni (ophthalmologists), Alice Bertoletti (orthoptist), Vannia Avigo (psychologist) for their valuable professional assistance in evaluating the children in this study. The authors are also grateful to the Italian Angelman Syndrome associations OR.S.A. and Associazione Angelman for their kind support.
Funding

Not applicable.

Availability of data and material

Data have been shared in the tables included in the article.

\section{Authors' contributions}

MS participated in the design of the study, performed the neuropsychological evaluation, helped to draft the manuscript. PF, MP participated in the design of the study, performed the neurological (motor and physical) evaluation, helped to draft the manuscript, helped to draft the manuscript. AP, GL, TV enrolled the patients. GJ participated in the design of the study, performed the visual evaluation, helped to draft the manuscript. FE coordinated and participated in the design of the study and helped to draft the manuscript. All authors read and approved the final manuscript.

\section{Competing interests}

The authors declare that they have no competing interests.

\section{Consent for publication}

Consent for the publication was obtained from the parents' participants.

Ethics approval and consent to participate

Ethical Committee of ASST Spedali Civili of Brescia, Italy (committee reference number NP 1302) approved the study and informed consent was obtained from parents' patients.

\section{Author details}

${ }^{1}$ Unit of Child Neuropsychiatry and Early Neurorehabilitation, ASST Spedali Civili, Piazzale Spedali, Civili 1, 25123 Brescia, Italy. ${ }^{2}$ Cognition Psychology Neuroscience Lab, University of Pavia, Pavia, Italy. ${ }^{3}$ Department of Clinical and Experimental Sciences, University of Brescia, Brescia, Italy. ${ }^{4}$ Unit of Child Neurology and Psychiatry, ASST Spedali Civili, Piazzale Spedali Civili 1, 25123 Brescia, Italy.

Received: 15 April 2016 Accepted: 12 October 2016

Published online: 21 October 2016

\section{References}

1. Kishino T, Lalande M, Wagstaff J. UBE3A/E6-AP mutations cause Angelman syndrome. Nat Genet. 1997;15:70-3

2. Dagli A, Buiting K, Williams CA. Molecular and clinical aspects of Angelman syndrome. Mol Syndromol. 2011;2:100-12.

3. Varela MC, Kok F, Otto PA, Koiffmann CP. Phenotypic variability in Angelman syndrome: comparison among different deletion classes and between deletion and UPD subjects. Eur J Hum Genet. 2004;12:987-92.

4. Gentile JK, Tan WH, Horowitz LT. A neurodevelopmental survey of Angelman syndrome with genotype-phenotype correlations. J Dev Behav Pediatr. 2010; 31:592-601.

5. Williams CA, Beaudet AL, Clayton-Smith J, Knoll JH, Kyllerman M, Laan LA et al. Angelman syndrome 2005: updated consensus for diagnostic criteria. Am J Med Genet A. 2006;140:413-8.

6. Williams CA, Driscoli DJ, Dagli Al. Clinical and genetic aspects of Angelman syndrome. Genet Med. 2010;12:385-95.

7. Clayton-Smith J, Laan L. Angelman syndrome: a review of the clinical and genetic aspects. J Med Genet. 2003;40:87-95.

8. Pelc K, Cheron G, Dan B. Behavior and neuropsychiatric manifestations in Angelman syndrome. Neuropsychiatr Dis Treat. 2008;4:577-84.

9. Bird LM. Angelman syndrome: review of clinical and molecular aspects. Appl Clin Genet. 2014;7:93-104

10. Mertz LG, Christensen R, Vogel I, Hertz JM, Østergaard JR. Eating behavior prenatal and postnatal growth in Angelman syndrome. Res Dev Disabil. 2014;35:2681-90.

11. Peters SU, Goddard-Finegold J, Beaudet AL, Madduri N, Turcich M, Bacino CA. Cognitive and adaptive behaviour profiles of children with Angelman syndrome. Am J Med Genet. 2004;128:110-3.

12. Andersen WH, Rasmussen RW, Strømme PS. Levels of cognitive and linguistic development in Angelman syndrome: a study of 20 children. Logoped Phoniatr Vocol. 2001;26:2-9.

13. Conant KD, Thibert RL, Thiele EA. Epilepsy and the sleep-wake patterns found in Angelman syndrome. Epilepsia. 2009;50:2497-500. 
14. Thibert RL, Conant KD, Braun EK, Bruno P, Said RR, Nespeca MP, et al. Epilepsy in Angelman syndrome: a questionnaire-based assessment of the natural history and current treatment options. Epilepsia. 2009;50:2369-76.

15. Williams CA. Neurological aspects of the Angelman syndrome. Brain Dev. 2005;27:88-94

16. Calculator SN. Parents' perceptions of communication patterns and effectiveness of use of augmentative and alternative communication systems by their children with Angelman syndrome. Am J Speech Lang Pathol. 2014;23:562-73.

17. Di Nuovo S, Buono S. Behavioral phenotypes of genetic syndromes with intellectual disability: comparison of adaptive profiles. Psychiatry Res. 2011; 189:440-5.

18. Brun Gasca C, Obiols JE, Bonillo A, Artigas J, Lorente I, Gabau E, et al. Adaptive behaviour in Angelman syndrome: its profile and relationship to age. J Intellect Disabil Res. 2010;54:1024-9.

19. Mah ML, Wallace DK, Powell CM. Ophthalmic manifestations of Angelman syndrome. J AAPOS. 2000;4:248-9.

20. Michieletto P, Bonanni P, Pensiero S. Ophthalmic findings in Angelman syndrome. J AAPOS. 2011;15:158-61.

21. Russell DJ, Rosenbaum PL, Avery LA, Lane M. In: Stefanoni G, editor. Gross Motor Function Measure (GMFM-66 E GMFM-88) - Manuale dell'utente. Roma: Armando; 2006

22. Roid GH, Miller $L$, Pomplun $M$, Koch C. Leiter international performance scale. 3rd ed. Firenze: Giunti OS; 2002.

23. Griffiths R. GMDS Griffiths Mental Developmental Scales 0-2. Firenze: Hoegrefe; 1996

24. Uzgiris IC, Hunt JMCV. Assessment in infancy: ordinal scales of psychological development. Urbana: University of Illinois Press; 1975

25. Piaget J. The origin of intelligence in children. New York: Int Univ Press; 1952.

26. Sparrow SS, Balla DA, Cicchetti DV. Vineland Adaptive Behavior ScalesSurvey form. Firenze: Giunti OS; 2003

27. Caselli MC, Casadio P. II primo vocabolario del bambino. Milano: Franco Angeli; 1995.

28. Riello M, Re AM, Cornoldi C. Costruzione di uno strumento rivolto alla famiglia per l'identificazione precoce del DDAI. Disturbi di Attenzione e Iperattività. 2005;1:9-26.

29. Fazzi E, Signorini SG, Bova SM, La Piana R, Ondei P, Bertone C, et al. Spectrum of visual disorders in children with cerebral visual impairment. J Child Neurol. 2007;22:294-301.

30. Zmarick C. L'emergere dei suoni dell'italiano in una prospettiva interlinguistica. In: Mariotta G, Costamagna L, editors. Acquisizione linguistica e teorie fonologiche. Pisa: Pacini; 2008. p. 43-65.

31. Bortolini U. Prove per la valutazione fonologica del linguaggio infantile. Padova: Master; 1995.

32. Penner KA, Johnston J, Faircloth BH, Irish P. Williams CA. Communication, cognition, and social interaction in the Angelman syndrome. Am J Med Genet. 1993:46:34-9.

33. Oller DK, Seibert JM. Babbling of prelinguistic mentally retarded children. Am J Ment Retard. 1988:92:369-75.

34. Wilson BJ, Sundaram SK, Huq AH, Jeong JW, Halverson SR, Behen ME, et al. Abnormal language pathway in children with Angelman syndrome. Pediatr Neurol. 2011;44:350-6.

35. Lee ST, Nicholls RD, Bundey S, Laxova R, Musarella M, Spritz RA. Mutations of the $\mathrm{P}$ gene in oculocutaneous albinism, ocular albinism, and Prader-Willi syndrome plus albinism. N Engl J Med. 1994;330:529-34.

36. Aghaji AE, Lawrence L, Ezegwui I, Onwasigwe E, Okoye O, Ebigbo P. Unmet visual needs of children with Down syndrome in an African population: implications for visual and cognitive development. Eur J Ophthalmol. 2013; 23:394-8.

37. Fazzi E, Signorini SG, La Piana R, Bertone C, Misefari W, Galli J, et al. Neuroophthalmological disorders in cerebral palsy: ophthalmological, oculomotor, and visual aspects. Dev Med Child Neurol. 2012;54:730-6.

\section{Submit your next manuscript to BioMed Central and we will help you at every step:}

- We accept pre-submission inquiries

- Our selector tool helps you to find the most relevant journal

- We provide round the clock customer support

- Convenient online submission

- Thorough peer review

- Inclusion in PubMed and all major indexing services

- Maximum visibility for your research

Submit your manuscript at www.biomedcentral.com/submit

) Biomed Central 